\section{DUST EXPLOSIONS.}

THE explosion of a mixture of dust and air, supposed by the head of the firm of Messrs. Bibby Brothers to have been the initiating cause of the catastrophe which destroyed and set on fire part of their oil-cake and seed-crushing mills in Liverpool on the night of November 24, is the most probable explanation of that occurrence. It appears that some of the seeds which contain no oil form an exceedingly fine powder when crushed. The hypothesis is that fine powder produced in this manner became disseminated in the air of the chamber, thus forming an inflammable mixture, and was ignited by some means not ascertained, possibly by a stream of sparks due to friction between the grinding rolls, possibly by an open light. Be this as it may, a violent explosion took place, shattering that portion of the mill in which crushing is carried on, and causing the deaths of thirty-one persons, and, more or less, serious injuries to I I 2 others.

This event recalls the disastrous explosion which destroyed the Tradeston Flour Mills in Glasgow in 1872 , and was investigated and reported upon by Profs. Rankine and Macadam. On that occasion Prof. Macadam stated: "When the whole of the conditions required theoretically for the most disastrous explosions are practically realised, the increase of pressure is equal to eight atmospheres, or 120 lbs. per square inch, which must necessarily bring about a violent explosion and wreck any ordinary building."

Another notable explosion of the same kind, which stands unrivalled in the magnitude of the havoc wrought by it, wrecked the Washburn Flour Mills at Minneapolis on May 2, I878, and set fire to six other mills and a number of buildings in the neighbourhood. Profs. Peckham and Rye, who were commissioned by the coroner's jury to investigate the circumstances in which it took place, made a series of experiments in closed boxes to test the explosibility of a variety of powdered substances, amongst others various flour mixtures and coal dust. The powders were blown into the box with bellows and ignited by an open light. As the result of their experiments the investigators came to the conclusion "that practically all finely divided highly carbonaceous material would explode under the conditions tried."

Explosions in grinding mills are not, perhaps, so infrequent as might be imagined: a dust explosion occurred in an adjoining block in Messrs. Bibby's mill four years ago, when several workmen were injured, and many similar explosions have taken place in flour mills from time to time, causing damage and setting fire to the buildings, but not heard of beyond the immediate locality, and then probably reported merely as fires.

Most mill owners seem to be now alive to the risks they run from this cause, and take the precaution of limiting the dimensions of the spaces in which mixtures of dust and air are necessarily formed, and excluding open flames from them. Besides flour mills, sugar refineries, starch works, and factories for the preparation of madder, lycopodium powder, flour of sulphur, and so on, have all been the scenes of explosions of this kind. Lycopodium powder, which consists of the spores of $L$. clavatum, the staghorn moss, is amongst the most inflammable of these substances. It burns with a sudden flash of yellow flame and with a hissing noise, probably due to the bursting of the individual spores, when its mixture with air is ignited.

Lastly, the inflammable, and under certain conditions explosive, nature of a mixture of air and coal No. 2 I96, VOL. 88] dust is now becoming better understood and appreciated, and has recently constituted the subject oi articles contributed by the present writer to the pages of NATURE (vol. Ixxxvi., pp. 223, 595).

W. Galloway

\section{THE TEACHING OF MATHEMATICS. ${ }^{1}$}

THESE two reports on mathematical teaching cover very different ground, and are treated from very different points of view. The report of the London County Council refers particularly to elementary schools, though in many places it deals with general questions of mathematical teaching that apply to schools of all types. The New South Wales report refers entirely to the work of secondary schools. Again, the L.C.C. report is drawn up by a body consisting mainly of teachers in the closest touch with the child, and, throughout their report, they consider the state of development of the child's mind and the wide differences there must be between the children in the future. In marked contrast to this, the N.S.W. report does not seem to be based on an intimate knowledge of the minds of average pupils, but seems to aim only at the production of future mathematicians.

The L.C.C. report opens with a chapter devoted to general questions of mathematical teaching; then follows an excellent chapter on the first steps in arithmetic. The next chapter, "On the coordination of arithmetic with science and other subjects of the curriculum," is the most suggestive chapter in the report; there are many excellent suggestions for changing the arithmetic lesson from a dull grind to a really attractive lesson, instilling into the pupils a truly scientific spirit. The only doubt that arises in our mind is whether the second-rate teacher will keep a proper balance between the illustrations leading up to new ideas and the new ideas themselves-recent experience in geometry shows that a word of warning is necessary. The fourth chapter deals with the logical and computative sides of the subject-some of the examples considered seem to be the diabolical inventions of the examiner or the text-book writer. Finally, we have a summary of the answers to questions sent round to teachers, examiners, and inspectors-some of these are of great interest; the most interesting perhaps is taken in the first chapter; it deals with the "relative capacity of boys and girls for mathematics":-

"Opinions expressed were in favour of a greater general capacity for mathematics, especially as tested by the solution of problems, among boys, and of greater neatness, accuracy, and conscientiousness in carrying out rules and processes, among girls. It was, however, stated that many brilliant exceptions were to be found amongst the girls. The evidence further went to show that the genius is balanced by the dullard more often among groups of boys than among groups of girls."

Altogether, the report is one of the most suggestive contributions that have been made to the literature on mathematical teaching in schools. We commend it most heartily to all teachers in secondary as well as elementary schools.

In the N.S.W. report there is a paragraph near the beginning which lays stress on the importance of coordination in teaching the various branches of mathematics, but it is not worked out in detail, and seems to break down in one or two places; e.g. in the second year trigonometry is included under arithmetic, whereas

1 London County Council. Education Committee. Report of a Conference on the Teaching of Arithmetic in London Elementary Schools. December 1906-December 1908. Pp. 134. (London: P. S. King and Co.,

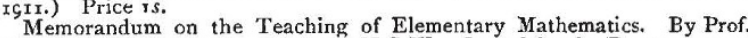
H. S. Carslaw. Pp. 3r. (Sydney, N.S.W. : Issued by the Department of Public Instruction, n.d.) 
trigonometry, including the definitions and numerical work, is not begun until the third year. In arithmetic stress is laid on the importance of a grasp of principles, and reference is made to the harm text-books have done in the way of multiplying rules and setting up mere trivial examples as important types. We do not know the average age of entry to the secondary schools of N.S.W., but we doubt whether pupils in their first year are sufficiently mature in mind for such questions as "Retail and Banker's Discount" and "Balance Sheets." In England arithmetic has suffered seriously by the introduction of the technicalities of commerce and the money market at too early an age. The second-year course is to go deeper into such things; we should have thought it wiser to postpone most of this work to the third or fourth year, and bring in more numerical trigonometry and easy mechanics to take its place-it is intended to do something of the sort in the second year as "simple problems on the lever, wheel and axle, and inclined plane" are included, but there are no suggestions as to the practical work on which to base these problems.

The section devoted to algebra begins with a philosophical treatment of negative and fractional quantities, but it is not proposed that pupils should be taken through such a treatment "in their first steps in algebra"; but the course suggested for the first two years is what schools in England have been trying to break away from in the last decade. The whole attitude seems to be too abstract for beginners-we should have liked to see the factors of $x^{3}+a^{3}$, long H.C.F., and the solution of two simultaneous equations, "in which only terms of the second degree and constant terms occur," all postponed until after the second year, and indices and logarithms brought back in their place. We feel that it would have been wiser to make the early treatment much less abstract and more numerical, and to let the fourth-year course include a more scientific treatment of the elements of the subject.

Differential calculus is introduced into the fourth year's algebra, but seems to be intended only for those who matriculate in higher mathematics. We should like to see a short introduction to both differential and integral calculus introduced into secondary schools for all pupils of average ability. The treatment suggested in this report for the differential is good, including, as it does, the principles of the subject without elaborating the technique--we suspect that integral calculus is meant to be included as reference is made to the evaluation of areas, \&c.

The report goes on to discuss geometry :-

"It is common knowledge that within the last few years the methods adopted in the teaching of geometry have been greatly altered. No less common is the belief that many of the changes which have been made have hardly justified themselves, that the relative importance of the various parts of the subject has been frequently forgotten, that much unsatisfactory reasoning is being accepted as logical, and that much unnecessary confusion exists. . . A boy who has made a comparatively close acquaintance with straight lines, angles, circles, triangles, parallelograms, \&c., by actual drawing and measurement, knows far more of their properties than one who has learnt by heart long lists of definitions and some of Euclid's propositions. And when, by a carefully graduated series of experiments and drawings, he has discovered for himself the fundamental theorems regarding congruen triangles, the theory of parallels, the measurement of areas, and the circle, he is ready to proceed to the study of deductive geometry, and should profit by that study in many different ways.

"This is the first, and one of the most important, of the changes which have been made in the teaching of geometry; but, with regard to it, some words of warning are still necessary. There is no doubt that the role of NO. 2196 , VOL. 887 experiment, careful drawing, exact measurement, and calculation from the figures drawn by the pupils has been exaggerated."

With all this we agree most heartily, but with Prof. Carslaw's remedy we cannot agree; this practically amounts to taking the theorems of Euclid to the end of parallels, and setting them up as a standard order to be followed by all schools. Prof. Carslaw seems to feel that such a retrograde step is likely to meet with opposition, for he says: "Without prescribing rigid adherence to the scheme drawn up and embodied in its programme, the Department intends to base its instruction upon it." This seems to give the teacher the choice the famous Hobson gave to his customers when they came to hire horses. We can only express our deep regret that such a retrograde step should be deemed necessary in N.S.W. to remedy an evil which is doubtless the same in all its features as that we are experiencing in England.

The evil may be considered to be due to two distinct causes: (i) some teachers have not shown a proper appreciation of what constitutes a sound logical proof, and have let their pupils use slipshod arguments; (ii) pupils have a break in their careers when they pass from the elementary to the secondary schools. With regard to (i) it may be pointed out that practically all teachers, both in England and Australia, have had their training in geometry under a cast-iron system, viz. that of Euclid; some teachers under that system have acquired a splendid appreciation of what is logical, but the very existence of the evil referred to proves that other teachers have not acquired that appreciation-this does not point to finding the remedy in another cast-iron system, particularly one closely following the lines of Euclid.

Doubtless a rigid system would remedy the difficulty of transition from school to school, but that difficulty ought never to exist; for, as Prof. Carslaw points out, the only trouble due to the lack of a standard order lies in the fundamental theorems about congruence, and parallels and the angle-sum for a triangle; and that part of geometry, in our opinion, should not be treated deductively before the age of fourteen with any but pupils of very exceptional mathematical ability, and possibly not with them. It will be remembered that a couple of years ago the Board of Education published a circular recommending that these fundamental theorems be arrived at by induction, and then taken as a base on which to build up a logical system of deductive geometry. Prof. Carslaw says :-

"With this advice I find myself unable to agree. One of my reasons for disagreeing with their method is that I am sure the difficulty that these fundamental congruence theorems offer to the pupil is exaggerated, and that 1 believe the reasoning, by means of which they are to be proved, can be of value to him. Another ground for my dissent from the plan of that circular is that the treatment of parallels which it recommends, by its introduction of the idea of direction as fundamental, and by making the angle-sum theorem independent of the theory of parallels, includes one of those fallacies with which the long history of that theory is crowded."

We wonder whether Prof. Carslaw has seen the advice of the Board carefully followed by sympathetic teachers; it is generally found that the results of teaching on these lines are much better than those where a deductive treatment of congruence, \&c., is attempted-there is greater knowledge of geometry, greater appreciation of logical geometry, and more power to tackle new work. We must differ from Prof. Carslaw when he says the difficulty of the congruence theorems is exaggerated-in a comparatively wide experience of boys, we have never found the proofs of these theorems clearly understood until the boy has 
had some further acquaintance with deductive geometry in the form of riders and later propositions, though in many cases the proofs have been learnt for purposes of reproduction.

Again, Prof. Carslaw objects to the use of the idea of direction in dealing with parallels and the angle-sum theorem-we should quite agree with him that such a treatment would not be satisfactory in a deductive course, but we differ most strongly from him in thinking that a deductive treatment of parallels, \&c., is necessary or wise in the first two years of geometry. The fact is, deductive geometry is not a suitable study for children before the age of twelve, and even at that age it must be a difficult study, and the deductive treatment of congruence and parallels is one of the most difficult parts of the subject, and should certainly not precede the deductive treatment of the parallelogram and the circle. We can only regret that New South Wales has been frightened by difficulties which were bound to arise in a period of transition, into going back to the old methods instead of boldly remedying the evil by helping all teachers to get the spirit of the new methods.

The report goes on to consider trigonometry and mechanics, but there is nothing that calls for serious comment.

R. Y. S.

\section{TSETSE-FLIES AND SLEEPING SICKNESS.}

A DEPUTATION representing eight missionary societies at work in Nyasaland waited upon the Secretary of State for the Colonies on November 23 in order to urge that game restrictions should be removed over a whole or part of the protectorate, on the ground that the tsetse-fly was suspected of spreading sleeping sickness, and that the destruction of big game "might" eliminate the fly. In his reply, Mr. Harcourt very wisely deprecated hasty action in a matter in which "the best-informed people were the least positive as to the facts."

It is by no means certain that the destruction of the larger mammalian fauna would have any such effect as the members of the deputation seem to anticipate. In the first place, it is highly probable that the primary host of the trypanosome of sleeping sickness is man, and that if the trypanosome is now to be found in wild mammals in regions in which the disease is known to have been introduced in recent times, it is because it has been transmitted to them from human beings by the agency of the tsetse-flies. Secondly, it is very far from certain that the destruction of the larger mammalia would have the effect of eliminating tsetse-flies, which can suck the blood of any kind of vertebrate animal, and which swarm in parts of the Uganda Protectorate (for example, on small uninhabited islands in the Victoria Nyanza) where there are no larger mammalia. Thirdly, the danger must be reckoned with that to deprive the tsetses of a large portion of their natural food-supply might have the effect of forcing them to supplement the deficiency elsewhere, and might therefore render them much more aggressive towards men and domestic animals, and in this way more efficient in spreading trypanosome diseases.

Everyone with a knowledge of the complicated problems involved in the subject of the transmission of trypanosomes by tsetses will deprecate ill-considered destruction of the big game, an action which, while robbing large tracts of country of one of their most beautiful and valuable features, may very well have the effect of upsetting the balance of nature in a manner that would greatly aggravate the evils which it is desired to combat.

NO. 2 I96, VOL. 88]
THE INTERNATIONAL CONFERENCE AT PARIS ON NAUTICAL ALMANACS.

$\mathrm{N}$ the initiative of the Bureau des Longitudes, the directors of the various national ephemerides were invited by $M$. Baillaud, director of the Paris Observatory, to assemble there on Monday, October 23. The objects of the reunion were to consider what steps, if any, should be taken to extend the scope of the various ephemerides for the purposes of astronomy, and at the same time to effect economy by combined action and interchange of computations. A small number of the leading practical astronomers were also invited to represent the needs of astronomy of precision.

The first general meeting was held at the Observatory at Io a.m., Monday, October 23. On the motion of Sir David Gill, M. Baillaud took the chair, having on his right $M$. Bayer, secrétaire de l'enseignement supérieure, representing M. Steeg, Ministre d'Instruction publique.

On the motion of M. Baillaud, Sir David Gill, as président d'honneur du Congrès de la Carte du Ciel, was nominated président d'honneur of the reunion, Dr. O. Backlund, imperial astronomer of Russia, vicepresident, and $\mathrm{Mr}$. $\mathrm{H}$. Andoyer, of the Bureau of the Connaissance des Temps, together with the Comte de la Baume Pluvinel, were nominated secretaries. There were present:-Prince Roland Bonaparte (member of the Academy of Sciences); Messrs. Cowell ("Nautical Almanac," London), Fritz Cohn (Berlin), Eichelberger (Washington), Général de Azcarate (San Fernando), Boccardi (Turin), as directors of ephemerides; Messrs. Dyson (astronomer royal, Greenwich), Hough (H.M. astronomer, Cape of Good Hope), Perrine (Cordoba), André (Lyons), Picart (Bordeaux), Verschaffel (d'Abbadia), as directors of observatories; and, as representatives of the Bureau des Longitudes MM. Bigourdan (president), Poincaré, Radau Deslandres, Hanusse.

The meeting was opened with an admirable address by $M$. Baillaud, and with a cordial speech of welcome by $M$. Bayer on behalf of the Minister of Public Instruction. After some discussion, resolutions, recommending the adoption as soon as possible of Greenwich mean time as the argument for all predictions in nautical and astronomical ephemerides, were unanimously passed. In the afternoon of the same day the members of the congress attended by invitation the meeting of the Academy of Sciences at the institute, and in the evening were entertained at a banquet in the Observatory, at which M. Steeg, Minister of Public Instruction, was present. The toast of "The President of the French Republic" was proposed by Sir David Gill, to which an interesting and eloquent speech was made, in reply, by $M$. Steeg. The health of M. Baillaud was proposed by Dr. Backlund.

Further meetings of the congress were held on October 24 and 25, and at the conclusion of the meeting on October 25 a unanimous agreement on all points was reached. On Thursday, October 26, the directors of the nautical almanacs met in committee to make final cooperative arrangements and report to the general congress; their report was unanimously adopted at an afternoon meeting on the same day.

A translation of the resolutions adopted is subjoined. It is impossible to overrate the good will and cordiality which pervaded the meeting, or the kindness and hospitality of our hosts. Besides the official banquet on Monday, private dinner-parties were given by M. Andoyer on the Tuesday, by M. Baillaud on the Thursday evening, the latter followed by a reception; a luncheon and reception were also given on the Friday afternoon by. Prince Roland Bonaparte, and 